\title{
Diagnóstico da Infecção pelo HPV em Lesões do Colo do Útero em Mulheres HIVt: Acuidade da Histopatologia
}

\author{
Histopathology Accuracy for the Diagnosis of HPV in Cervical \\ Lesions of HIV-seropositive Women
}

Néli Sueli Teixeira de Souza, Victor Hugo do Melo, Lúcia Porto Fonseca de Castro

\begin{abstract}
RESUMO
Objetivo: comparar a acurácia do estudo histopatológico e da reação em cadeia por polimerase (PCR) no diagnóstico da infecção pelo papilomavírus humano (HPV) em lesões do colo uterino de mulheres infectadas pelo virus da imunodeficiência humana (HIV).

Métodos: foram estudadas 52 mulheres soropositivas para o HIV com lesões cervicais clinicamente suspeitas de HPV nas quais se realizou raspado ectocervical para a PCR e biópsia dirigida pela colposcopia, para o estudo histopatológico. As amostras de três pacientes se mostraram sem qualidade para a PCR, reduzindo a população estudada para 49.

Resultados: a prevalencia de HPV foi de 53\% pela histopatologia e de $85,7 \%$ pela PCR. Dentre as 42 pacientes com HPV detectado pela PCR, 26 foram confirmadas pela histopatologia (sensibilidade $=61,9 \%$ ). Esta, por sua vez, não demonstrou nenhum resultado falso-positivo (especificidade $=100 \%$ ), com predição positiva de 100\%. Comparando-se os dois resultados, encontrou-se para a histopatologia: valor preditivo positivo $=100 \%$ e valor preditivo negativo = 30,4\%. Das 26 pacientes com histopatologia positiva para HPV, 15 (57,6\%) apresentaram neoplasias intra-epiteliais cervicais (NIC). O risco relativo de uma paciente com HPV apresentar NIC foi de 13,3.

Conclusão: a histopatologia mostrou 100\% de acerto para o diagnóstico de HPV, o que significa dizer que, quando a biópsia for positiva o HPV certamente estará presente, confirmando a suspeita clínica. No entanto, a baixa sensibilidade retira da histopatologia o valor como exame de rastreamento nesse grupo de mulheres.
\end{abstract}

PALAVRAS-CHAVE: Reação em cadeia por polimerase. Papilomavirus humano. AIDS. Colo do útero: lesões pré-neoplásicas.

\section{Introdução}

Dezenove anos se passaram desde a primeira notificação de casos de síndrome da imunodeficiência adquirida (AIDS). Desde então a doença vem se espalhando por todo o mundo e a Organização Mundial de Saúde (OMS) estima que cerca de 36,1 milhões de pessoas estejam contaminaCentro de Treinamento e Referência de Doenças Infecciosas e Parasitárias (CTR-DIP)

do Hospital das Clinicas da Universidade Federal de Minas Gerais (UFMG)

Serviço de biópsias do Departamento de Anatomia Patológica e Medicina Legal da Faculdade de Medicina da UFMG

Núcleo de Pesquisa e Apoio Diagnóstico (NUPAD) da Faculdade de Medicina da UFMG

Correspondência:

Néli Sueli Teixeira de Souza

Rua Ouro Fino, 177 apto. 901 - Cruzeiro

30310-110 - Belo Horizonte - MG das com o virus atualmente ${ }^{1}$.

No momento a AIDS representa a principal causa de morte de adultos entre 20 e 50 anos em 15 países. O Brasil e o mundo continuam altamente vulneráveis ao HIV que, durante a próxima década, provavelmente será o maior determinante de mortalidade nesta faixa etária em praticamente todos os países do mundo ${ }^{2}$.

De acordo com o Centro de Prevenção e Controle de Doenças (CDC) de Atlanta, em pessoas infectadas com o HIV a doença é definida por uma série de condições, tais como infecções oportunistas, doenças do sistema nervoso central (SNC) e tumores como o sarcoma de Kaposi, linfomas primitivos do SNC não-Hodgkin e linfomas de células B. O aumento da incidência de neoplasias cervicais no trato genital inferior de mulheres infectadas pelo HIV induziu o CDC a incluir o car- 
cinoma cervical entre as condições definidoras de AIDS $^{3}$.

No estudo do carcinoma cervical o interesse pelo HPV cresceu desde que zur Hausen ${ }^{4}$, na década de 70, sugeriu a associação entre o HPV e o câncer cervical. Vários estudos epidemiológicos, clínico-patológicos e moleculares se seguiram, confirmando o papel do HPV na patogênese do câncer cervical e em suas lesões precursoras ${ }^{5,6}$.

Apesar dos vários estudos publicados e de tudo que já se conhece a respeito da infecção pelo HPV e neoplasia cervical em mulheres portadoras do HIV, muitas dúvidas levantadas permanecem sem resposta, incluindo o melhor seguimento para essas pacientes, estratégia de vigilância, o papel dos diferentes tipos de HPV e a identificação de fatores independentes, preditivos do desenvolvimento da doença.

A relação entre HIV, HPV e o desenvolvimento de lesões precursoras do câncer cervical é sem dúvida complexa e ainda não está completamente compreendida. O comportamento sexual de risco pode predispor à aquisição de ambas as infecções, dificultando o estudo da relação de causa e efeito $^{7}$. Por outro lado, acredita-se que o estado de imunocompetência do hospedeiro possa ter algum papel na evolução das lesões cervicais. A imunossupressão induzida pelo HIV aumenta a suscetibilidade à infecção por $\mathrm{HPV}^{8}$.

A natureza da infecção por HPV na mulher soropositiva para o HIV pode ser também alterada, levando-se em consideração o tipo de vírus, as infecções por múltiplos tipos e infecções por tipos inespecíficos ${ }^{9,10}$, que poderiam explicar a doença cervical mais avançada nessas pacientes. Além disso, os efeitos do HIV e do HPV na resposta imune da mucosa e as interações diretas entre HIV/ HPV em nivel molecular devem ser consideradas ${ }^{11}$, incluindo o efeito de proteína tat do HIV, modulando a expressão gênica do HPV ${ }^{12,13}$.

Enquanto o tratamento estiver limitado a técnicas ablativas e excisionais, as neoplasias cervicais em mulheres HIV-positivas devem ser precocemente diagnosticadas como única forma de prevenir a progressão dessas lesões. O câncer invasivo nessas pacientes tem comportamento mais agressivo, responde mal às terapias preconizadas e, na recorrência, é de pior prognóstico ${ }^{7}$.

Em nosso meio, o diagnóstico das neoplasias intra-epiteliais cervicais nessas pacientes é firmado por meio de biópsias de lesões cervicais. É o resultado do estudo anatomopatológico que determina o tratamento.

A observação, em estudos anteriores ${ }^{14}$, de resultados negativos para HPV em biópsias de pacientes com diagnóstico molecular positivo nos induziu a pesquisar o real valor do diagnóstico histopatológico para HPV em pacientes infectadas pelo HIV.

\section{Pacientes e Métodos}

Este estudo foi aprovado pela Câmara do Departamento de Ginecologia e Obstetrícia da Faculdade de Medicina da UFMG, pelo Serviço de Doenças Infecciosas e Parasitárias do Hospital das Clínicas de Belo Horizonte e pelo Comitê de Ética em Pesquisa da UFMG. As pacientes, após orientadas sobre a pesquisa, assinaram o documento de consentimento.

No período de abril de 1998 a setembro de 1999, todas as pacientes soropositvas para HIV que compareceram ao Centro de Treinamento e Referência de Doenças Infecciosas e Parasitárias (CTR-DIP) da UFMG para a sua primeira consulta ginecológica e possuíam lesões cervicais foram incluídas no estudo. Foram excluídas as pacientes grávidas.

Todas as pacientes apresentavam teste sorológico positivo para HIV segundo a Portaria no 488, de 17 de junho de 1998, da Secretaria de Vigilância Sanitária do Ministério da Saúde. A contagem de linfócitos $\mathrm{CD}^{+}$foi realizada com o uso de anticorpos monoclonais para uso comercial e pela citometria de fluxo. O número absoluto dos linfócitos $\mathrm{CD}^{+}$foi calculado baseado na contagem total de linfócitos. O valor considerado foi do exame mais próximo da primeira consulta ginecológica. De acordo com os resultados as pacientes foram agrupadas segundo classificação do CDC de $1993^{3}$. No grupo estudado, 41 pacientes $(83,6 \%)$ faziam uso de drogas anti-retrovirais.

Essas pacientes, na maioria das vezes, foram encaminhadas pelo serviço da Clínica Médica com queixas ginecológicas, ou simplesmente para exame de rotina. Todas foram submetidas a um questionário do protocolo de atendimento ginecológico. Dados demográficos, uso de drogas, álcool, fumo, comportamento sexual, número de parceiros, etc., foram registrados. Após anamnese foi realizado o exame clínico e ginecológico, que incluiu um completo exame pélvico. O exame clínico-ginecológico seguiu normas estabelecidas pelo serviço e também foi realizado de acordo com o protocolo.

Todas as pacientes portadoras de lesões cervicais foram biopsiadas e os resultados foram comparados aos resultados de PCR realizados em raspados dessas lesões. A PCR foi escolhida como padrão em nosso estudo por ser um método de alta sensibilidade e especificidade para HPV.

Para o cálculo amostral foi utilizado o pro- 
grama Epi-Info versão $6.04 \mathrm{~b}^{15}$. Com base na prevalência da infecção por HPV estimada pela literatura, que varia de 3,7 a $47,9 \%$, calculou-se que seriam necessários 80 pacientes, com uma margem de perda de $15 \%$ já incluída. No presente estudo a prevalência encontrada foi de $85,7 \%$, o que reduziu a amostra necessária para atingir o objetivo do trabalho. Das 52 pacientes que participaram do estudo, 3 tiveram amostras sem qualidade para PCR e, portanto, foram desconsideradas.

Inicialmente, após a colocação de espéculo vaginal, com o auxilio de uma espátula de Ayre, foi realizado coleta de material cervical para a realização da PCR para HPV. O material foi colhido pela autora do estudo, por meio de raspado cauteloso do colo uterino para não desencadear sangramentos. A espátula de Ayre era então partida com o intuito de diminuir seu comprimento para que coubesse em um tubo de ensaio e permitisse seu completo fechamento com uma tampa de borracha. O tubo de ensaio continha em torno de $1,5 \mathrm{ml}$ de soro fisiológico, de forma que todo o material ficasse mergulhado em soro. Se o colo uterino se apresentasse normal à colposcopia e ao teste de Schiller, a amostra para PCR era desprezada. Se houvesse lesão clinicamente suspeita de HPV, o tubo era rotulado e deixado em geladeira até o final de cada atendimento, quando então era entregue ao Núcleo de Pesquisa e Apoio Diagnóstico (NUPAD) da UFMG.

As amostras entregues ao NUPAD foram conservadas em geladeira a $4^{\circ} \mathrm{C}$ até seu processamento (24-48 $\mathrm{h}$ após a entrega). Com o objetivo de extrair o DNA, as amostras foram inicialmente homogeneizadas, transferidas para tubos de Eppendorf $(1,5 \mathrm{ml})$ e centrifugadas por 1 minuto a $14.000 \mathrm{rpm}$, para a formação do pellet. O sobrenadante foi desprezado e ao pellet foram adicionados $200 \mu \mathrm{l}$ de Chelex-100 a 20\% (resina quelante). A mistura, após passar pelo Vortex para ser homogeneizada, ainda nos tubos de Eppendorf, foi fervida por 20 minutos e colocada em geladeira até a preparação.

Para pesquisa de HPV foram utilizados 2 procedimentos de PCR: o primeiro para a detecção e o segundo para a tipagem. Primeiramente, foi feito o mix de detecção para o diagnóstico qualitativo. Quando o resultado foi positivo, procedeu-se à tipagem. Para a reação de detecção foram utilizados 2 pares de primers: o "geral" e o "consensus".

Para controle da extração, utilizou-se um par de primers que amplifica o gene da globina (a presença da globina atesta a qualidade da amostra, ou seja, existe DNA adequado para a PCR).

A Tabela 1 resume as possibilidades de leitura na interpretação da PCR. São apresentadas as seqüências dos primers utilizados no NUPAD para a tipagem específica do HPV "consensus", "geral" e $\beta$-globina, após processamento no termociclador. Foram consideradas sem qualidade as amostras nas quais não se obteve a amplificação da globina, sendo estas excluídas.

Tabela 1 - Interpretação dos resultados do procedimento da PCR.

\begin{tabular}{cccc}
\hline Globina & Geral & Consensus & Resultado \\
\hline Negativo & Negativo & Negativo & Amostra sem qualidade \\
Positivo & Negativo & Negativo & Negativo \\
Positivo & Positivo & Negativo & Positivo \\
Positivo & Negativo & Positivo & Positivo \\
Positivo & Positivo & Positivo & Positivo \\
\hline
\end{tabular}

As amostras positivas foram tipadas para os vírus dos tipos $6,11,16,18,31,33$ e 35 . Para cada tipo de HPV existe um par de primers. Para cada amostra, foram realizadas 7 reações para os tipos a serem pesquisados.

Para evitar contaminação com DNA estranho foram utilizadas salas independentes para cada uma das seguintes etapas: extração do DNA, preparação do mix, procedimento da PCR e eletroforese.

O passo seguinte foi a coleta de material para citologia oncótica, com espátula de Ayre e escova ("cytobrush"). Os laudos foram emitidos segundo classificação de Bethesda e/ou Papanicolaou.

Para a colposcopia foi utilizado o colposcópio da marca Liesegang, modelo padrão. A colposcopia foi realizada após aplicação de ácido acético a 3\% sobre o colo uterino com o objetivo de pesquisar áreas aceto-brancas. Após essa primeira avaliação colposcópica, o colo foi corado com solução de Schiller e novamente observado ao colposcópio. Toda área iodo-negativa foi estudada, assim como a presença de pontilhados, mosaico, etc., e o desenho da lesão foi registrado no prontuário de cada paciente. O passo seguinte foi a aplicação de solução de bissulfito de sódio a 5\% para "descolorir" o colo. O ácido acético a 3\% foi reaplicado e novamente foi realizado estudo colposcópico com o objetivo de relacionar as áreas aceto-brancas com as áreas iodo-negativas. Foram considerados achados colposcópicos anormais: epitélio aceto-branco, pontilhado, mosaico, leucoplasia, epitélio iodonegativo, vasos atípicos. Para classificação das lesões cervicais foi utilizada a nomenclatura proposta pelo Comitê da Federação Internacional de Patologia Cervical e Colposcopia, $1990^{16}$.

Toda lesão foi biopsiada sob visão colposcópica, utilizando-se pinça de Gaylor-Medina. 
O material biopsiado foi fixado em formol a $10 \%$ e processado para estudo histológico de rotina. Dos blocos de parafina foram realizados cortes histológicos com $5 \mathrm{~mm}$ de espessura, os quais foram corados pela hematoxilina-eosina e examinados na rotina do Serviço de Biópsias do Departamento de Anatomia Patológica e Medicina Legal da Faculdade de Medicina da UFMG. Posteriormente, foram examinadas por um único patologista, com padronização do laudo e levando-se em consideração: a amostragem (somente ectocérvice, somente endocérvice ou zona de transformação); presença de infiltrado inflamatório na lâmina própria e sua avaliação semiquantitativa; presença de neoplasias intra-epiteliais ou invasoras; presença do efeito citopático do HPV (cavitação citoplasmática perinuclear com espessamento da membrana citoplasmática, atipia nuclear e anisocitose) e presença de outros agentes especificos.

A análise e descrição histopatológica seguiu orientação de Wright et al. ${ }^{17}$, baseada na classificação proposta por Richart ${ }^{18}$.

Foram classificadas como NIC I as lesões que apresentavam o terço basal do epitélio acometido por células com distúrbio de polarização e maturação. As lesões que apresentavam dois terços basais do epitélio acometido por células com pleomorfismo moderado, aumento da relação núcleo/citoplasma e cromatina granular foram classificadas como NIC II. Como NIC III, foram classificadas as lesões que apresentavam mais de dois terços do epitélio acometido por células com pleomorfismo acentuado, cromatina granulosa e nucleomegalia acentuada. Nesse grupo também foram incluídas as lesões que acometiam todo o epitélio, porém, sem sinais de invasão.

Foram classificadas como cervicite crônica inespecífica as lesões que apresentavam importante infiltrado inflamatório mononuclear com tecido de granulação e fibrose do estroma.

Os dados foram armazenados e analisados no software Epi-Info, versão 6.0. Para análise da distribuição de freqüência foi empregado o teste do $\chi^{2}$ ou teste exato de Fisher. Foi considerado o valor de $5 \%(\mathrm{p}<0,05)$ como limiar de significância estatística, com poder de detecção de $80 \%$ ( $ß=$ $0,2)$.

\section{Resultados}

Das 49 biópsias realizadas, 7 (14,2\%) apresentavam metaplasia escamosa e/ou cervicite crônica; $16(32,6 \%)$ apresentavam algum grau de displasia, ao passo que $26(53,1 \%)$ detectaram a presença de HPV (Tabela 2). Dentre os 26 casos positivos para HPV, $15(57,7 \%)$ apresentavam displasia associada. Do total de 16 casos de displasia cervical, 15 (93,75\%) estavam associados à infecção por HPV (RR = 13,3) (Tabela 2). A infecção pelo HPV esteve associada à lesão de baixo grau (LSIL) em 90\% dos casos e à lesão de alto grau (HSIL) em $100 \%$ dos casos (Tabela 3 ).

Tabela 2 - Associação entre a infecção pelo HPV detectado à histopatologia e presença de neoplasia intra-epitelial cervical.

\begin{tabular}{lccc}
\hline Infecção pelo HPV & \multicolumn{3}{c}{ Associação com displasia } \\
& Presente & Ausente & Total \\
\hline Presente & 15 & 11 & 26 \\
Ausente & 1 & 22 & 23 \\
Total & 16 & 33 & 49 \\
\hline
\end{tabular}

$\chi^{2}=13,46 ; p=0,0002 ; R R=13,27 ;$ IC $(1.90<0 R<92.80)$

Tabela 3 - Associação entre infecção pelo HPV e grau das lesões cervicais à histopatologia.

\begin{tabular}{lcccccc}
\hline Infecção & \multicolumn{3}{c}{ Grau de displasia } & Ausência & Total \\
pelo HPV & NIC I & NIC II & NIC III & de displasia & \\
\hline Presente & 9 & 5 & 1 & 11 & 26 \\
Ausente & 1 & 0 & 0 & 22 & 23 \\
Total & 10 & 5 & 1 & 33 & 49 \\
\hline
\end{tabular}

$\mathrm{p}=0,73$. NIC, neoplasia intra-epitelial cervical.

Com relação ao tipo, o HPV foi classificado, para fins práticos, em baixo risco $(6,11)$ e alto risco $(16,18,31,33,35)$ para o desenvolvimento de câncer cervical. Os HPV de alto risco estavam presentes em 15 dos 16 casos (93,7\%) das displasias cervicais, ao passo que em apenas 1 caso $(6,3 \%)$ a displasia esteve relacionada à HPV de baixo risco (Tabela 4).

Tabela 4 - Associação entre o tipo de HPV e presença de lesões cervicais.

\begin{tabular}{|c|c|c|c|c|c|}
\hline \multirow[t]{2}{*}{ Tipo* } & \multicolumn{3}{|c|}{ Grau de displasia } & \multirow{2}{*}{$\begin{array}{c}\text { Infecção pelo HPV } \\
\text { sem displasia }\end{array}$} & \multirow[t]{2}{*}{ Total } \\
\hline & NIC I & NIC II & NIC III & & \\
\hline Baixo risco & 1 & 0 & 0 & 9 & 10 \\
\hline Alto risco & 8 & 6 & 1 & 16 & 31 \\
\hline Total & 9 & 6 & 1 & 25 & 41 \\
\hline
\end{tabular}

Entre os 42 resultados positivos para HPV à PCR, o tipo de HPV não pôde ser determinado em apenas um caso. A infecção por múltiplos tipos de 
HPV foi observada em 25 pacientes (59,5\%). Dessas, apenas uma não apresentava tipos de alto risco. Dezesseis pacientes apresentaram infecção simples (por apenas um tipo de HPV) $(38,1 \%)$. Os tipos mais prevalentes foram o 6 e 16 , ocorrendo em 48,9 e $36,7 \%$ dos casos, respectivamente.

Na Tabela 5, é apresentado o resultado da PCR e da histopatologia para HPV. Verificou-se que a PCR foi positiva em $42(85,7 \%)$ das 49 pacientes estudadas, ao passo que a histopatologia foi positiva em 26 (53\%). A histopatologia não fez o diagnóstico de HPV em 16 pacientes (38\%). Não houve falso-positivo; sempre que a histopatologia foi positiva a PCR confirmou a presença do virus.

Tabela 5 - Comparação entre a histopatologia e a PCR para diagnóstico de HPV.

\begin{tabular}{lccc}
\hline Histopatologia & \multicolumn{2}{c}{ PCR } & Total \\
& Positiva & Negativa & \\
\hline Positiva & 26 & 0 & 26 \\
Negativa & 16 & 7 & 23 \\
Total & 42 & 7 & 49 \\
\hline
\end{tabular}

Teste de Fisher; $p=0,003$

sensibilidade $=61,9 \% ;$ IC: $[45,6-76,0]$

especificidade $=100 \% ;$ IC: $[56,1-100]$

valor preditivo positivo $=100 \%$; IC: $[84-100]$

valor preditivo negativo $=30,4 \%$; IC: $[14,1-53]$

Quando relacionamos a contagem de $\mathrm{CD}^{+}$ com os resultados positivos para HPV obtidos pela PCR, das 47 que foram submetidas a contagem de $\mathrm{CD}^{+}$, observamos que em $40(85,1 \%)$ a PCR era positiva para HPV. Dentre essas, $37(78,7 \%)$ tinham contagem $\mathrm{CD}^{+}{ }^{+}$menor que $499 / \mathrm{mm}^{3}$. Entretanto, não houve relação entre freqüência de infecção por HPV e niveis de $\mathrm{CD}^{+}(\mathrm{p}=0,6)$.

Ao relacionarmos os resultados dos testes de PCR entre as pacientes soropositivas e as portadoras de AIDS, também não foi observada significância estatística quanto à prevalência do HPV $(p=0,1)$. Quanto ao tipo de HPV, observamos que os tipos de alto risco foram mais prevalentes nas pacientes com número de células $\mathrm{CD}^{+}$abaixo de 499 do que os tipos de baixo risco.

Entre as 26 pacientes com histopatologia positiva para HPV, $15(57,6 \%)$ eram soropositivas para HIV e 11 (42,3\%) eram portadoras de AIDS $(p=0,6)$.

\section{Discussão}

Embora a prevalência de HPV possa variar com o método de detecção utilizado, em nossa amostra $85,7 \%$ dos casos apresentavam PCR posi- tiva, o que não contraria estudos realizados anteriormente, também em mulheres infectadas pelo HIV, em que encontrou-se prevalência de HPV de $75,1 \%^{8}$ e de $73 \%{ }^{15}$, com diagnóstico de NIC em $45 \%$ das pacientes ${ }^{10}$. Em nosso estudo a histopatologia diagnosticou HPV em 53\% dos casos. Entre os 26 resultados positivos, $15(57,6 \%)$ estavam associados a algum grau de displasia: 9 tinham NIC I, 5 tinham NIC II e 1 caso tinha NIC III.

Observamos maior freqüência de infecção por múltiplos tipos virais, o que segundo alguns autores é observado quando se utiliza a PCR. É ainda comum a observação de infecção por tipos indeterminados ${ }^{19}$. Os tipos mais prevalentes de HPV no trato anogenital têm sido divididos em três grupos: de baixo risco, de risco intermediário e de alto risco, conforme o seu potencial oncogênico. Os mais freqüentes são: de baixo risco, os tipos 6 e 11; de risco intermediário, 31,33 e 35 , e de alto risco os tipos 16 e $18^{20}$.

Os tipos de HPV de alto risco foram mais prevalentes do que os de baixo risco entre as pacientes com contagem de células $\mathrm{CD}^{+}$abaixo de $499 / \mathrm{mm}^{3}$. A diferença, entretanto, não foi estatisticamente significativa.

Em nosso estudo, foi possivel relacionar a infecção pelo HPV de alto e baixo risco com o grau de displasia. Entre os 42 resultados positivos para HPV, 1 não determinou o sorotipo, 31 mostraram HPV de alto risco e 10 HPV de baixo risco. Dos 31 casos envolvendo HPV de alto risco, 15 estavam relacionados a displasias cervicais: 8 NIC I, 6 NIC II e 1 NIC III. Portanto, 7 casos de lesão cervical de alto risco eram decorrentes de infecção por HPV de alto risco. A PCR diagnosticou HPV de alto risco em $76 \%$ dos casos e, entre esses, $22,6 \%$ tinham lesão cervical de alto grau (NIC II-III). Em estudo no qual se avaliaram 168 mulheres soropositivas para o HIV ${ }^{21}, 54$ foram submetidas à biópsia. Entre essas, 41 (76\%) tinham lesão de baixo grau (73\% tinham HPV de alto risco e 17\% HPV de baixo risco) e $9(16,6 \%)$ apresentavam lesão de alto grau (HPV de alto risco em 89\% e HPV de baixo risco em $11 \%)$. Quatro biópsias foram negativas para HPV.

No presente estudo, quando o diagnóstico de HPV realizado pela PCR foi comparado aos resultados das biópsias, verificamos que a histopatologia apresentou sensibilidade de $61,9 \%$, especificidade de $100 \%$, valor preditivo positivo de $100 \%$ e valor preditivo negativo de $30,4 \%$. Ficou demonstrado que quando a histopatologia fez o diagnóstico de HPV, o seu acerto foi de $100 \%$. O elevado número de falso-negativos (38\%) nos obriga a continuar a investigação, caso haja lesão cervical.

$\mathrm{Na}$ literatura pesquisada não foram encontrados trabalhos comparando os resultados da histopatologia e PCR para o diagnóstico de HPV em 
mulheres infectadas pelo HIV.

Em geral se afirma que a infecção por HPV e o grau de displasia cervical em pacientes infectadas pelo HIV estão diretamente relacionados ao grau de imunossupressão. É relatado que até $70 \%$ das mulheres HIV positivas, com contagem de $\mathrm{CD}^{+}$abaixo de 200 células $/ \mathrm{mm}^{3}$, têm infecção cervical pelo HPV ${ }^{22}$. Nossos resultados no entanto não confirmaram esse achado. Uma possível explicação talvez seja o fato de grande parte da amostra estudada ser de pacientes em uso de drogas anti-retrovirais $(83,6 \%)$.

O impacto da terapia anti-retroviral no desenvolvimento e progressão das NIC ainda não foi definido. Uma primeira informação veio de um estudo no qual foi encontrada diferença notável na gravidade da displasia entre mulheres tratadas com e sem $\mathrm{AZT}^{10}$. De acordo com os autores não foi possivel obter conclusões porque os dois grupos (tratado e não-tratado) não eram homogêneos para o estudo da imunossupressão.

Em análise univariada o HPV per se, os tipos oncogênicos e a infecção múltipla foram os únicos fatores de risco para o diagnóstico histopatológico de NIC e esteve relacionado à imunossupressão (CD4 ${ }^{+}$abaixo de 200 células/ $\mathrm{mm}^{3}$ ). A imunossupressão e o tipo de HPV foram os fatores de risco mais importantes para desenvolvimento de NIC. Mulheres HIV positivas, com $\mathrm{CD}^{+}$abaixo de 200 células $/ \mathrm{mm}^{3}$, tiveram 16 vezes mais risco de NIC à citologia ${ }^{8}$.

Levando-se em conta a contagem de células $\mathrm{CD}^{+}$, a metade de nossa amostra era constituída de pacientes portadoras de AIDS $\left(\mathrm{CD}^{+}\right.$abaixo de 200 células $/ \mathrm{mm}^{3}$ ). A prevalência de HPV entre as pacientes portadoras do HIV e entre as doentes não foi diferente quando utilizamos a histopatologia e a PCR.

Concluindo, a histopatologia mostrou acerto de $100 \%$ para o diagnóstico de HPV, o que significa dizer que, quando a biópsia for positiva, o HPV certamente estará presente, confirmando a suspeita clínica. No entanto, a baixa sensibilidade retira da histopatologia o valor como exame de rastreamento do HPV em mulheres infectadas pelo HIV.

Apesar de não ter sido objetivo do estudo, foi possivel comprovar que as pacientes HIV positivas, infectadas pelo HPV, têm 13,3 vezes mais chance de desenvolver NIC do que as não portadoras de HPV.

\section{SUMMARY}

Purpose: to compare histopathology and polymerase chain reaction (PCR) for the diagnosis of human papillomavirus
$(H P V)$ in cervical lesions of human immunodeficiency virus (HIV)-seropositive women.

Methods: fifty-two HIV-seropositive women with suspected $H P V$ cervical lesions were studied. Cervical scrapes were collected for PCR and colposcopy-guided biopsy was made for the histopathologic study. Three samples were disqualified for PCR, leaving a study population of 49 women. Results: the prevalence of HPV was $53 \%$ by histopathology and $85.7 \%$ by PCR. Among the 42 patients in whom HPV was detected by PCR, 26 were confirmed by histopathology (sensitivity $=61.9 \%)$. This method gave no false-positives (specificity $=100 \%)$, with $100 \%$ of positive prediction. Compared to PCR, the histopathology had: positive predcitive value $=100 \%$ and negative predcitive value $=$ $30.4 \%$. Among the 26 patients with HPV-positive biopsy, 15 (57.7\%) had cervical intraepithelial neoplasia (CIN); relative risk $=13.3$.

Conclusion: histopathology was 100\% correct for HPVinfection diagnosis. It means that when the biopsy is positive, $H P V$ will be present, confirming the clinical suspicion. However, the low sensitivity excludes histopathology as a screening examination in this group of women.

KEY WORDS: Histology. Polymerase chain reaction. Human: papillomavirus - diagnosis. HIV infection. Uterine cervix: neoplasms.

\section{Referências}

1. World Health Organization (WHO). Global Summary of the HIV/AIDS epidemic. www.who.int [online] Dec. 2000 [acessado 2001 jul. 11]. Disponivel em URL:http://www.unaids.org/wac/2000/ wad00/file/WAD epidemic report.htm.

2. Brasil. Ministério da Saúde. Perguntas e respostas sobre HIV/AIDS. [online] c116, 1999 nov. [acessado em dez/2000]. Disponível em: www.aids.gov.br/livro/c116.htm.

3. CDC: 1993. Revised classification system for HIV infection and expanded surveillance case definition for AIDS among adolescents and adults. JAMA 1993; 269: 729-30

4. zur Hausen H. Viruses in human cancers. Science 1991; 25:1167-73.

5. Schiffman MH. Recent progress in defining the epidemiology of human papillomavirus infection and cervical neoplasia. J Natl Cancer Inst 1992; 84:394-8.

6. Wright TC Jr, Richart RM. Role of human papillomavirus in the pathogenesis of genital tract warts and cancer. Gynecol Oncol 1990; 37:151-64.

7. Maiman M, Fruchter RG, Sedlis A, et al. Prevalence, risk factors, and accuracy of cytologic screening 
for cervical intraepithelial neoplasia in women with the human immunodeficiency virus. Gynecol Oncol 1998; 68:233-9.

8. Petry KU, Scheffel D, Bode U, et al. Cellular immunodeficiency enhances the progression of human papillomavirus-associated cervical lesions. Int J Cancer 1994; 57:836-40.

9. Johnson JC, Burnett AF, Willet GD, Young MA, Doniger J. High frequency of latent and clinical human papillomavirus cervical infections in immunocompromised human immunodeficiency virus infected women. Obstet Gynecol 1992; 79:321-27.

10. Maiman M, Tarricone N, Vieira J, Juarez J, Serur E, Boyce JG. Colposcopic evaluation of HIVseropositive women. Obstet Gynecol 1991; 78:84-8.

11.Spinillo A, Tenti P, Zappatore R, Seta F, Silini E, Guaschino S. Langerhans' cell counts and CIN in women with HIV infection. Gynecol Oncol 1993; 48:210-3.

12.Tornesello ML, Buonaguro FM, Beth-Giraldo B, Giraldo G. Immunodeficiency virus type 1 tat gene enhances HPV early gene expression. Intervirology 1993; 36:57-64.

13.Vernon S, Hart CE, Reeves WC, Icenogle JP. The HIV-1 tat protein enhances E2-dependent HPV 16 transcription. Virus Res 1993; 27:133-45.

14. Campos RR. Prevalência do Papiloma Virus Humano (HPV) e seus genotipos, na cérvice uterina, em mulheres portadoras e não portadoras do Vírus da Imunodeficiência Humana (HIV) [dissertação]. Belo Horizonte: Universidade Federal de Minas Gerais; 1999.
15.Dean AG, Dean JA, Coulombier D, et al. Epi Info, Version 6: a word processing, database, and statistics program for epidemiology on microcomputers. Centers of Disease Control and Prevention, Atlanta, Georgia, 1994.

16.Terminologia Colposcópica da Federação Internacional de Patologia Cervical e Colposcopia (IFCPC), 1990. In: Gross G, Barrasso R. Infecções por papilomavirus humano: Atlas Clínico de HPV. Porto Alegre; 1999. p. 207.

17.Wright TC, Kurman RJ, Kurman J, Ferenczy A. Precancerous lesions of the cervix. In: Kurman RJ, editor. Blaustein's Pathology of the Female Genital Tract. $4^{\text {th }}$ ed. New York: Springer-Verlag; 1994. p. 229-77.

18. Richart RM. Cervical intraepithelial neoplasia. Pathol Annu 1973; 8:301-28.

19.Chang DY, Chen RJ, Lee SC, Huang SC. Prevalence of single and multiple infection with human papillomaviruses in various grades of cervical neoplasia. J Med Microbiol 1997; 46:54-60.

20.Wieland U, Pfister H. Papilomavírus em patologia humana: epidemiologia, patogênese e papel oncogênico. In: Gross G, Barrasso R., editores. Infecções por Papilomavírus Humano: atlas clínico de HPV. 1a ed. Porto Alegre: Artes Médicas; 1999. p.1-18.

21.Uberti-Foppa C, Origoni M, Maillard M, et al. Evaluation of the detection of human papillomavirus genotypes in cervical specimens by hybrid capture as screening for precancerous lesions in HIV-positive women. J Med Virol 1998; 56:133-37.

22.Phillips-P. No plateau for HIV/AIDS epidemic in US women. J Am Med Assoc 1997; 277:1747-9. 